\title{
SCIENTIFIC REPORTS

\section{Characterization and Interpretation of Cd (II) Adsorption by Different Modified Rice Straws under Contrasting Conditions}

\author{
Shuai Wang ${ }^{1,2,5^{*}}$, Nan Wang ${ }^{1,5}$, KaiYao $^{3}$, Yuchuan Fan ${ }^{2}$, Wanhong $\mathrm{Li}^{1}$, Weihua Han ${ }^{1}$, \\ Xinhua Yin ${ }^{4 *} \&$ Dianyuan Chen ${ }^{1 *}$
}

Rice straw can adsorb Cd(II) from wastewater, and modification of rice straw may improve its adsorption efficiency. The rice straw powder (Sp) from the direct pulverization of rice straw was used as the control, the rice straw ash (Sa), biochar ( $\mathrm{Sa}$ ), and modified rice straw (Ms) were prepared by ashing, pyrolysis and citric acid modification, respectively, and all of them were examined as adsorbents for $\mathrm{Cd}(\mathrm{II})$ in this study. Batch adsorption experiments were adopted to systematically compare the adsorption capacities of rice straw materials prepared with different modification methods for $\mathrm{Cd}(\mathrm{II})$ from aqueous solution under different levels of initial Cd(II) concentration $\left(0-800 \mathrm{mg} \cdot \mathrm{L}^{-1}\right)$, temperature $(298,308$, and $318 \mathrm{~K})$, contact time $(0-1440 \mathrm{~min}), \mathrm{pH}$ value $(2-10)$, and ionic strength $\left(0-0.6 \mathrm{~mol} \cdot \mathrm{L}^{-1}\right)$. The results indicated that the modification method affected the adsorption of $\mathrm{Cd}(\mathrm{II})$ by changing the specific surface area (SSA), Si content, surface morphology, and O-containing functional group of rice straw. Compared with Sp, Ms held more surface $\mathrm{O}-\mathrm{H}$, aliphatic and aromatic groups, while Sa had more phenolic, $\mathrm{C}-\mathrm{O}$ (or $\mathrm{C}-\mathrm{O}-\mathrm{C}$ ), and $\mathrm{Si}-\mathrm{O}$ groups, and $\mathrm{Sb}$ held more $\mathrm{C}-\mathrm{O}$ (or $\mathrm{C}-\mathrm{O}-\mathrm{C}$ ) and $\mathrm{Si}-\mathrm{O}$ groups; besides, $\mathrm{Sa}, \mathrm{Sb}$, and Ms had larger SSA than Sp. Adsorption capacity of the four adsorbents for $\mathrm{Cd}(\mathrm{II})$ increased and gradually became saturated with the increase in the initial Cd(II) concentration $\left(0-800 \mathrm{mg} \cdot \mathrm{L}^{-1}\right)$. The adsorption capacity of $\mathrm{Cd}(\mathrm{II})$ was significantly higher at $318 \mathrm{~K}$ than $298 \mathrm{~K}$ and $308 \mathrm{~K}$, regardless of the adsorbent type. Sa had the largest SSA $\left(192.38 \mathrm{~m}^{2} \cdot \mathrm{g}^{-1}\right)$ and the largest adsorption capacity for $\mathrm{Cd}(\mathrm{II})$. When the initial $\mathrm{Cd}^{2+}$ concentration was at $800 \mathrm{mg} \cdot \mathrm{L}^{-1}$, the $\mathrm{Cd}(\mathrm{II})$ adsorption amount reached as high as $68.7 \mathrm{mg} \cdot \mathrm{g}^{-1}$ with Sa at $318 \mathrm{~K}$. However, the SSA of Sp was only $1.83 \mathrm{~m}^{2} \cdot \mathrm{g}^{-1}$, and it had the least adsorption capacity for Cd(II). Only the adsorption of Cd(II) upon $\mathrm{Sb}$ at $298 \mathrm{~K}$ was spontaneous, and surprisingly, all other adsorptions were nonspontaneous. These adsorptions were all chemical, and were favorable, exothermic and order-increasing processes. The pseudo-second-order model showed a strong fit to the kinetics of $\mathrm{Cd}(\mathrm{II})$ adsorption by the four adsorbents. The adsorption capacities of $\mathrm{Cd}(\mathrm{II})$ by the adsorbents were less at low $\mathrm{pH}$, and all were enhanced with the increase of initial $\mathrm{pH}$ value (2-10) in the solution. The inhibiting effect on Cd(II) adsorption due to the increase in ionic strength was greater with $\mathrm{Sa}, \mathrm{Sb}$, and $\mathrm{Ms}$ than that under $\mathrm{Sp}$. The rice straw ash prepared by ashing unexpectedly had greater adsorption capacity for $\mathrm{Cd}(\mathrm{II})$ than the biochar and citric acid modified rice straw. The optimum condition for $\mathrm{Cd}(\mathrm{II})$ adsorption was established as the temperature of $318 \mathrm{~K}$, initial $\mathrm{Cd}(\mathrm{II})$ concentration of $800 \mathrm{mg} \cdot \mathrm{L}^{-1}$, contact time of $240 \mathrm{~min}$, and no $\mathrm{Na}(\mathrm{l})$ interference regardless of absorbent. In conclusion, rice straw ash shows the greatest potential of being applied to paddy fields for the remediation of $\mathrm{Cd}(\mathrm{II})$ pollution so as to reduce the risk of $\mathrm{Cd}(\mathrm{II})$ enrichment in rice grains and straws.

\footnotetext{
${ }^{1}$ Institute of Agriculture, Jilin Agricultural Science and Technology University, Jilin, 132101, China. ${ }^{2}$ Department of Biosystems Engineering and Soil Science, The University of Tennessee, Knoxville, TN, 37996, USA. ${ }^{3}$ College of Agricultural Sciences, Hainan University, Haikou, 570228, China. ${ }^{4}$ Department of Plant Sciences, The University of Tennessee, Jackson, TN, 38301, USA. ${ }^{5}$ These authors contributed equally: Shuai Wang and Nan Wang. *email: wangshuai419@126.com; xyin2@utk.edu; jlcdy@sina.com
} 
Cadmium $(\mathrm{Cd})$ is considered one of the most toxic and hazardous heavy metals due to its high mobility and biological accumulation, and can cause a potential threat to human life with prolonged exposure ${ }^{1-3}$. It can be introduced to the aquatic environment through a variety of anthropogenic activities, especially some industrial processes, such as the use of phosphate fertilizers containing $\mathrm{Cd}$ and the application of $\mathrm{Cd}$ in pigments and stabilizers for plastics ${ }^{3}$.

Rice is the most important food crop in China. As one of the most common agricultural wastes, rice straw can cause many environmental problems since it exists in enormous quantities and is not easy to handle or transport ${ }^{4}$. Direct open burning of rice straw in fields is a common practice for its disposal and causes serious air pollution. Due to the large quantity of hydroxyl, carboxyl, and carbonyl groups, etc. on the surfaces of cellulose, lignin, and hemicelluloses in the rice straw, chelation, ion exchange, and other reactions may occur when rice straw is in contact with heavy metal ions ${ }^{5}$. In addition, because rice straw contains silica, it can adsorb various pollutants from wastewater with high efficiency ${ }^{6}$. Hence, utilization of rice straw to remove $\mathrm{Cd}(\mathrm{II})$ from water may be an ideal choice for using waste materials to control pollution?

In order to separate and remove heavy metal pollutants from water bodies, several technologies, such as adsorption, ion exchange, membrane separation, coagulation/flocculation, reverse osmosis, electrodialysis, and chemical precipitation ${ }^{2}$, have been developed in recent years. Out of these technologies, adsorption is considered the most promising method because of its high efficiency, low cost, simple operation, fast response, and environmental friendliness ${ }^{1,8,9}$.

Regeneration, easy access, and low-cost were the criteria used in selecting a suitable adsorbent ${ }^{10,11}$. Raw rice straw could remove $\mathrm{Pb}(\mathrm{II})$ from water through biosorption and its maximum removal rate reached $94 \%$ under optimal conditions ${ }^{12}$. El-Sayed et al. ${ }^{13}$ reported that rice straw was an effective adsorbent for Cd(II), and its adsorption capacity was highly related to the adsorbent dosage, initial Cd(II) concentration, and initial pH. Ding et al. ${ }^{14}$ found that the main mechanism of Cd(II) biosorption by raw rice straw lay in the exchange between the $\mathrm{Cd}(\mathrm{II})$ pollutant and the $\mathrm{K}(\mathrm{I}), \mathrm{Na}(\mathrm{I}), \mathrm{Ca}(\mathrm{II})$, and $\mathrm{Mg}(\mathrm{II})$ cations in the rice straw, as well as the chelation of $\mathrm{Cd}(\mathrm{II})$ by the $\mathrm{C}=\mathrm{C}, \mathrm{C}-\mathrm{O}, \mathrm{O}-\mathrm{H}$ groups and carboxylic acids in the rice straw. Asuquo et al. ${ }^{8}$ showed that white yam tuber peels were an efficient adsorbent for removing $\mathrm{Cd}(\mathrm{II})$ from aqueous systems.

Chemical pretreatment of agricultural wastes could enhance and reinforce their functional group potential, and consequently increase the adsorption capacity of these biosorbents ${ }^{15}$. Ahmaruzzaman and Gupta ${ }^{6}$ observed that chemical and thermal treatment significantly increased the adsorption capacity of rice husks; however, this increase was dependent on the method and conditions used for the treatment. Ye et al. ${ }^{16}$ reported that modified rice husks possessed faster kinetics and greater adsorption capacity for $\mathrm{Cd}(\mathrm{II})$ than the raw rice husks owing to the changes in its surface structure. Guo et al. ${ }^{17}$ demonstrated that the effects of chemically modified maize straw on Cd(II) removal from aqueous solutions were influenced by adsorbent dosage, initial ion concentration, contact time, solution $\mathrm{pH}$, and temperature. Ong et al. ${ }^{18}$ found that the adsorption capacity of rice husks for Cd(II) increased after they were treated with nitric acid. Similarly, the adsorption capacity of rice straw was greatly enhanced through thermochemically modification with citric acid ${ }^{7}$. Wu et al. ${ }^{3}$ used the microwave-assisted alkalization and acid oxidation to synthesize two novel wheat straw adsorbents for increasing Cd(II) removal in simulated waterlogged paddy soil. Li et al. ${ }^{19}$ utilized three modified biochar materials from rape straw to remediate $\mathrm{Cd}$ (II) pollution in aqueous systems. Zhang et al. ${ }^{20}$ showed that the biochar modified with $\mathrm{H}_{2} \mathrm{O}_{2}-\mathrm{HNO}_{3}$ was more effective in removing $\mathrm{Cd}(\mathrm{II})$ from water than the rice straw-derived biochar. Feng et al. ${ }^{21}$ observed that when rice husks were heated at a high temperature of $700^{\circ} \mathrm{C}$, their adsorption capacity for $\mathrm{Pb}$ (II) and $\mathrm{Hg}$ (II) from the aqueous solution was enhanced because of the increased specific surface area. Rice husk ash showed significant advantage over rice husks in the removal of $\mathrm{Pb}$ (II) from aqueous solution ${ }^{22}$.

In summary, most researchers used only one certain modification method to treat crop straw and explored the reason for the increased adsorption of Cd(II). For crop straws such as rice straw, the differences in adsorption capacity of $\mathrm{Cd}$ (II) by crop straw prepared with different modification methods were not simultaneously and systematically compared under conditions with different influencing factors. Thus, the objectives of this research were to (1) examine the effects of different modification methods on rice straw including citric acid modification, ashing and thermal pyrolysis in an oxygen-deficient environment on the characteristics of rice straw adsorbents using scanning electron microscopy (SEM), Fourier transform infrared spectroscopy (FTIR), and Brunauer-Emmett-Teller (BET) specific surface area measurement instrument, and (2) investigate the influences of initial $\mathrm{Cd}$ (II) concentration, temperature, contact time, solution $\mathrm{pH}$, and ionic strength on the adsorption capacities of $\mathrm{Cd}(\mathrm{II})$ with the rice straw adsorbents and explore their differences in the adsorption amount of Cd(II).

\section{Materials and methods}

Preparation of rice straw adsorbents. Rice straw (Oryza sativa L.) was collected from the experimental station at Jilin Agricultural Science and Technology University, Jilin, China. The rice straw was washed after harvest, rinsed with distilled water, and then air dried for 2 weeks. Preparation of rice straw powder (Sp): The airdried rice straw was chopped into $10 \mathrm{~mm}$ length, directly pulverized with a grinder without any treatment, and passed through a $0.25-\mathrm{mm}$ sieve. Preparation of rice straw ash (Sa): The ground rice straw powder was placed in a thin stainless steel tray, and the bottom of the tray was burned with an alcohol lamp while continuously turning over the straw until fully ashed. Preparation of rice straw biochar (Sb): The chopped rice straw was placed in a $700-\mathrm{mL}$ ceramic crucible, covered with a lid, and pyrolyzed in the absence of oxygen using a muffle furnace. The temperature was raised at $20^{\circ} \mathrm{C} \cdot \mathrm{min}^{-1}$ and kept constant at $500^{\circ} \mathrm{C}$ for $2 \mathrm{~h}^{23}$. It was cooled down at room temperature and then ground to pass through a $0.25-\mathrm{mm}$ sieve. Preparation of citric acid modified rice straw (Ms): The rice straw powder was mixed with $0.6 \mathrm{~mol} \cdot \mathrm{L}^{-1}$ citric acid at a ratio of 1:12 (straw/acid, $w / v$ ); after stirring for $30 \mathrm{~min}$ at room temperature, the acidic straw slurries were placed in a stainless-steel tray and dried at $50^{\circ} \mathrm{C}$ in a forced-air oven. After $24 \mathrm{~h}$, the thermochemical reaction between acid and straw was followed by raising the oven 
temperature to $120^{\circ} \mathrm{C}$ for $90 \mathrm{~min}$. After cooling, the reacted products were washed with distilled water to remove excess citric acid. Lastly, the washed reacted products were dried until a constant weight was achieved, and were then cooled down in a desiccator ${ }^{4,7}$.

Characterization of rice straw adsorbents. Specific surface area (SSA) and pore volume of the four adsorbents were estimated using the BET nitrogen adsorption technique at $77.3 \mathrm{~K}$ in a specific surface and aperture analyzer [3H-2000PS1, Beishide Instrument Technology (Beijing) Co., Ltd., China]; Scanning electron microscope (SEM) imaging analysis was conducted with a field emission scanning electron microscope (Hitachi, SU8000, Tokyo, Japan) to compare the structural and surface characteristics of the four types of rice straw adsorbents, and the scale was $5 \mu \mathrm{m}$. For Fourier transform infrared spectroscopy (FTIR), the sample was dried in a vacuum oven at $100{ }^{\circ} \mathrm{C}$ for $3 \mathrm{~h}$ before measurement. A sample of $1.5 \mathrm{mg}$ was compressed under vacuum with $250 \mathrm{mg}$ of $\mathrm{KBr}$ at a pressure of $20 \mathrm{MPa}$. The pellets obtained were analyzed with an FTIR-850 spectrometer from Gangdong Sci \& Tech Development Co, Ltd. in China covering a frequency range of 4000 to $400 \mathrm{~cm}^{-1}$.

Cd(II) adsorption experiments. $\quad 0.05 \mathrm{~g}$ of an adsorbent was accurately weighed into a 50-mL polyvinyl tube, and then a certain concentration of $\mathrm{CdCl}_{2}$ and $\mathrm{NaCl}$ (a supporting electrolyte) was added. The Cd(II) adsorption experiments consisted of the following four parts. (1) For adsorption thermodynamics, the initial $\mathrm{Cd}(\mathrm{II})$ concentration was set at $0,20,40,80,120,200,300,400,500,600$ and $800 \mathrm{mg} \cdot \mathrm{L}^{-1}$, respectively. The isothermal adsorption experiments were carried out at three temperatures $(298 K, 308 K$, and $318 K)$ separately. (2) For adsorption kinetics, the initial Cd(II) concentration was $400 \mathrm{mg} \cdot \mathrm{L}^{-1}$, and the suspensions were shaken at an agitation rate of $150 \mathrm{r} \cdot \mathrm{min}^{-1}$ at $298 \mathrm{~K}, 308 \mathrm{~K}$, and $318 \mathrm{~K}$ for different contact times of $0,10,30,60,90,120,240$, $360,480,720$, and $1440 \mathrm{~min}$, respectively. (3) For the influence of $\mathrm{pH}$ values, the temperature was $298 \mathrm{~K}$, the initial $\mathrm{Cd}(\mathrm{II})$ concentration was $400 \mathrm{mg} \cdot \mathrm{L}^{-1}$, and the initial $\mathrm{pH}$ value was set to $2,3,4,5,6,7,8,9$, and 10 , respectively, with $0.1 \mathrm{~mol} \cdot \mathrm{L}^{-1} \mathrm{NaOH}$ or $\mathrm{HCl}$. The final $\mathrm{pH}$ value was referred to as the $\mathrm{pH}$ value of the equilibrium solution at the end of adsorption. (4) For the effect of ionic strengths, the temperature was at $298 \mathrm{~K}$, the initial Cd(II) concentration was $400 \mathrm{mg} \cdot \mathrm{L}^{-1}$, and the ionic strength $(\mathrm{Na}(\mathrm{I}))$ was set to $0,0.004,0.01,0.04,0.1,0.2,0.4$, and $0.6 \mathrm{~mol} \cdot \mathrm{L}^{-1}$, respectively, using $\mathrm{NaCl}$ solution. The samples from each experiment were repeated three times.

The total volume of equilibrium solution was $25 \mathrm{~mL}$, and the adsorption experiments were carried out in a constant temperature water bath shaker for a predetermined time, shaking for $10 \mathrm{~h}$ and resting for $14 \mathrm{~h}$, except for adsorption kinetics. Then, the centrifuge tubes were taken out, centrifuged at $12,000 \mathrm{r} \cdot \mathrm{min}^{-1}$ for $10 \mathrm{~min}$, filtered, and diluted to a certain $\mathrm{Cd}$ (II) concentration, which was determined with an atomic absorption spectrophotometer (TAS 990) produced by Beijing Puxi General Co., Ltd. in Beijing, China. The amount of adsorbed Cd(II) at equilibrium $\left(q_{e}, \mathrm{mg}^{-1} \mathrm{~g}^{-1}\right.$ was calculated using the following equation (Eq. (1)):

$$
q_{e}=\left(C_{0}-C_{e}\right) V / m_{s}
$$

where $C_{0}$ and $C_{e}\left(\mathrm{mg} \cdot \mathrm{L}^{-1}\right)$ were the initial and equilibrium concentrations of $\mathrm{Cd}(\mathrm{II})$, respectively. $V(L)$ was the volume of the solution, and $m_{\mathrm{s}}(\mathrm{g})$ was the mass of adsorbent. All experiments were conducted with three replicates at room temperature. The $\mathrm{Cd}(\mathrm{II})$ concentration was reported as an average of the three replicates. The adsorption isotherm was modeled with the Langmuir (Eq. (2)), Freundlich (Eq. (3)) and Temkin (Eq. (4)) isotherm models, and the adsorption kinetics were simulated using the Lagergren's pseudo-first order (Eq. (5)) and pseudo-second-order (Eq. (6)) kinetic equations. All the data were calculated using the Origin 8.0 software.

$$
\begin{gathered}
q_{e}=\frac{q_{m} K_{L} C_{e}}{1+K_{L} C_{\mathrm{e}}} \\
q_{e}=K_{F} C_{e}^{1 / n} \\
q_{e}=B_{1} \ln \left(K_{T} C_{e}\right) \\
q_{t}=q_{e}\left(1-e^{-k_{1} t}\right) \\
q_{t}=\frac{k_{2} q_{e}^{2} t}{1+k_{2} q_{e} t}
\end{gathered}
$$

where $q_{e}$ and $q_{\mathrm{t}}\left(\mathrm{mg} \cdot \mathrm{g}^{-1}\right)$ were the adsorption capacity at equilibrium and time $t$, respectively; $k_{1}\left(\mathrm{~min}^{-1}\right)$ and $k_{2}\left(\mathrm{~g} \cdot \mathrm{mg}^{-1} \cdot \mathrm{min}^{-1}\right)$ were the rate constants corresponding to the respective kinetic model; $C_{e}\left(\mathrm{mg} \cdot \mathrm{L}^{-1}\right)$ was the residual $\mathrm{Cd}(\mathrm{II})$ concentration in the solution at equilibrium; $q_{m}\left(\mathrm{mg} \mathrm{g}^{-1}\right)$ represented the maximum adsorption capacity; $K_{L}\left(\mathrm{~L} \cdot \mathrm{mg}^{-1}\right)$ was the Langmuir adsorption constant related to the free energy of adsorption; $K_{F}\left(\mathrm{mg}^{-1}\right)$ was a constant in the Freundlich model relating to the adsorption capacity; and $1 / n$ was an empirical parameter relating to the adsorption intensity, which varied with the heterogeneity of the material. $B_{1}$ was the Temkin constant related to the heat of adsorption $\left(\mathrm{kJ} \cdot \mathrm{mol}^{-1}\right)$, and $K_{T}\left(\mathrm{~L} \cdot \mathrm{mg}^{-1}\right)$ was the equilibrium binding constant relating to the maximum binding energy ${ }^{8}$.

For the Langmuir model, to determine whether the adsorption system was favorable or not, the isotherm was classified with the separation factor $\left(R_{L}\right)$, which was calculated with the following equation (Eq. (7) $)^{24,25}$ : 


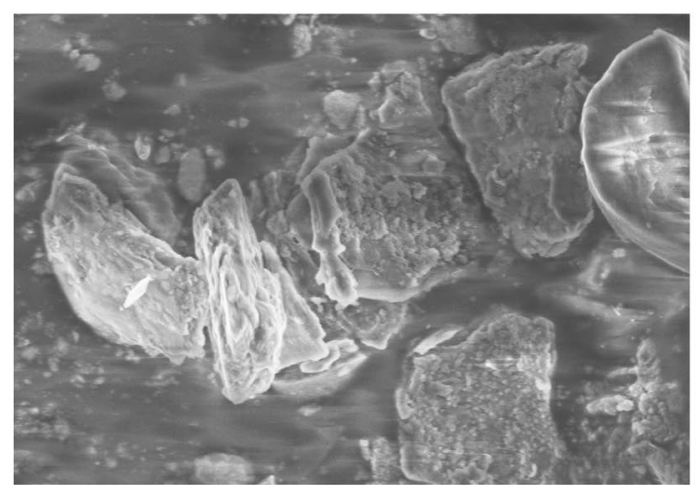

(Sp)

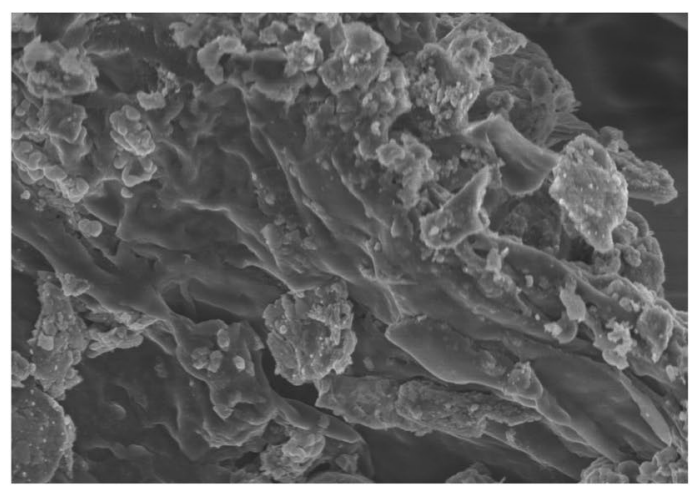

(Sb)

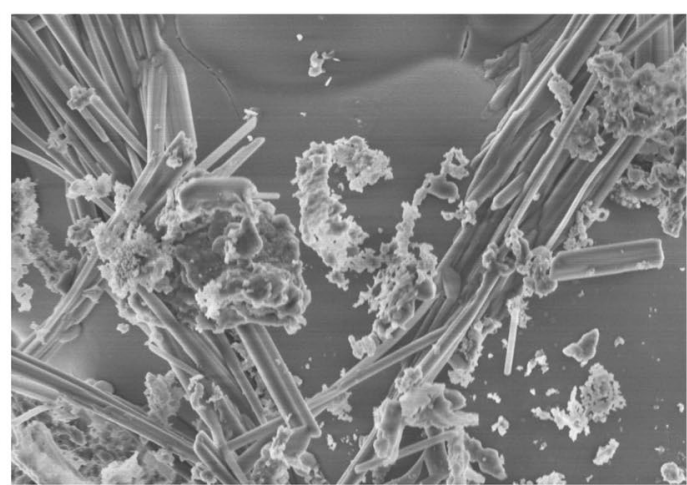

(Sa)

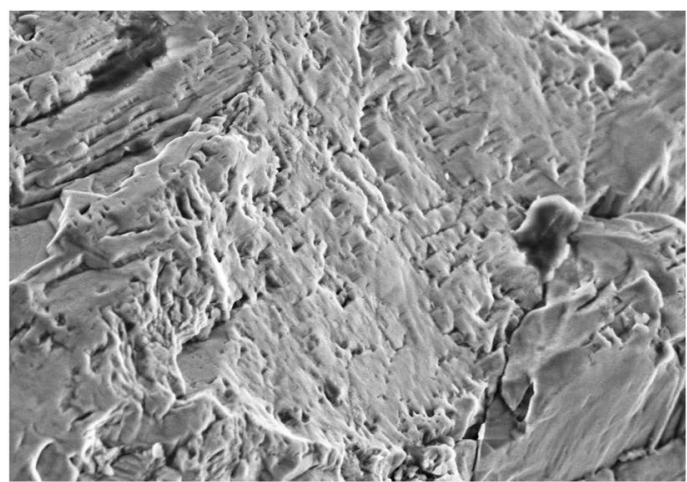

(Ms)

Figure 1. SEM images of the four rice straw adsorbents at 10,000x resolution $(5 \mu \mathrm{m})$. Sp, rice straw powder; Sa, rice straw ash; $\mathrm{Sb}$, rice straw biochar; and Ms, modified rice straw.

$$
R_{L}=\frac{1}{1+K_{L} C_{0}}
$$

To describe the thermodynamic behavior of the adsorption of Cd(II) onto the four rice straw biosorbents, thermodynamic parameters, such as Enthalpy change $\left(\Delta H^{\circ}\right)$, Gibbs free energy change $\left(\Delta G^{\circ}\right)$ and Entropy change $\left(\Delta S^{\circ}\right)$ were estimated. The thermodynamic parameters of the sorption reaction were assessed with the following equations (Eq. (8) and Eq. (9) $)^{26}$ :

$$
\begin{gathered}
\Delta G^{\circ}=-R T \ln \left(K_{L}\right) \\
\Delta G^{\circ}=\Delta H^{\circ}-T \Delta S^{\circ}
\end{gathered}
$$

where $T$ was thermodynamic temperature $(K)$; $R$ was the gas constant $\left(8.314 \mathrm{~J} \cdot \mathrm{mol}^{-1} \cdot K^{-1}\right)$; and $K_{L}$ was the equilibrium constant obtained from the Langmuir isotherm.

\section{Results and discussion}

Characterization of the adsorbents. The $\mathrm{N}_{2}$-BET specific surface area (SSA) was 1.83, 192.38, 16.47, and $3.17 \mathrm{~m}^{2} \cdot \mathrm{g}^{-1}$ and the pore volume was $0.016,0.228,0.045$, and $0.020 \mathrm{~cm}^{3} \cdot \mathrm{g}^{-1}$ for Sp, Sa, Sb, and Ms, respectively. Ahmaruzzaman and Gupta ${ }^{6}$ showed that the modification of rice husks could remove lignin and hemicellulose, reduce cellulose crystallinity, and increase the porosity or surface area. The SSA and pore volume results presented the same trend in our study, indicating that the microstructure and pore properties of rice straw benefited from the modification ${ }^{27}$. The Tiron-extractable Si contents were $41.2,182.3,168.5$, and $20.1 \mathrm{~g}^{\mathrm{kg}} \mathrm{kg}^{-1} \mathrm{in} \mathrm{Sp}, \mathrm{Sa}, \mathrm{Sb}$, and Ms, respectively, according to the analytical method of Guntzer et al. ${ }^{28}$.

The SEM image of Sp in Fig. 1 (Sp) showed Sp had a granular structure with irregular plates and cracks on its coarse surface ${ }^{6,25}$. The SEM image of Sa in Fig. 1 (Sa) showed that Sa had a large number of needle structures. The $\mathrm{SEM}$ image of $\mathrm{Sb}$ in Fig. 1 (Sb) showed there were many wrinkles on the surface of $\mathrm{Sb}$, and its edges had more granular structures. The SEM image of Ms in Fig. 1 (Ms) showed that Ms had a porous structure. It was obvious that different modification methods exerted different effects on the surface morphology of rice straw, which might affect the removal of Cd(II) by rice straw from water. 


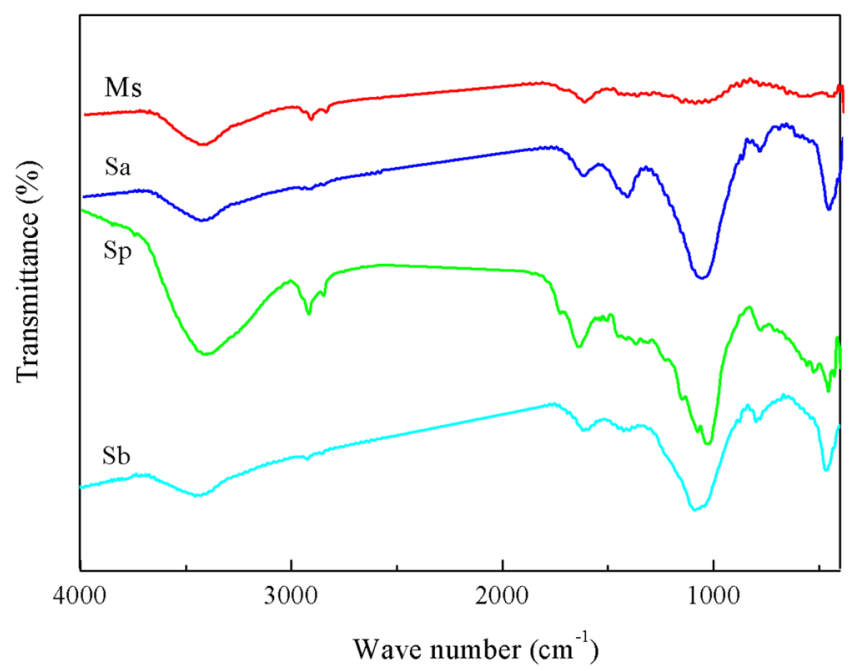

Figure 2. FTIR spectra of the four rice straw adsorbents. Sp, rice straw powder; Sa, rice straw ash; Sb, rice straw biochar; Ms, modified rice straw.

\begin{tabular}{|l|l|l|l|l|l|l|l|l|l|l|}
\hline \multicolumn{2}{|l|}{ Treatments } \\
\hline \multirow{3}{*}{ Ms } & Positions $\left(\mathrm{cm}^{-1}\right)$ & 3423 & 2924 & 2852 & & 1630 & & 1074 & & \\
\cline { 2 - 13 } & Relative intensities (\%) & 61.93 & 2.78 & 0.49 & & 9.31 & & 25.49 & & \\
\hline \multirow{3}{*}{ Sa } & Positions $\left(\mathrm{cm}^{-1}\right)$ & 3438 & 2920 & 2858 & & 1630 & 1419 & 1066 & 793 & 463 \\
\cline { 2 - 12 } & Relative intensities (\%) & 18.73 & 0.38 & 0.09 & & 2.90 & 5.43 & 58.30 & 1.74 & 12.43 \\
\hline \multirow{3}{*}{ Sp } & Positions $\left(\mathrm{cm}^{-1}\right)$ & 3404 & 2922 & 2852 & 1734 & 1647 & 1373 & 1036 & & 461 \\
\cline { 2 - 12 } & Relative intensities (\%) & 50.15 & 2.14 & 0.10 & 0.10 & 5.23 & 3.42 & 38.66 & & 0.20 \\
\hline \multirow{2}{*}{ Sb } & Positions $\left(\mathrm{cm}^{-1}\right)$ & 3454 & 2924 & 2854 & & 1616 & 1398 & 1088 & 798 & 467 \\
\cline { 2 - 11 } & Relative intensities (\%) & 22.83 & 0.35 & 0.15 & & 3.99 & 1.43 & 58.40 & 3.17 & 9.67 \\
\hline
\end{tabular}

Table 1. Relative intensities (\%) of the characteristic peaks existed in the four rice straw adsorbents. Sp, rice straw powder; Sa, rice straw ash; Sb, rice straw biochar; Ms, modified rice straw.

The FTIR spectra of four rice straw adsorbents were presented in Fig. 2. The characteristic peaks' position and spectral assignment for the adsorbents were shown in Table 1. As could be seen from Fig. 2, the FTIR spectra of four adsorbents had characteristic peaks at $3404 \sim 3454 \mathrm{~cm}^{-1}$ and $2924 \sim 2852 \mathrm{~cm}^{-1}$, which could be attributed to the $\mathrm{O}-\mathrm{H}$ stretching vibration corresponding to the aliphatic moieties in lignin and polysaccharides (cellulose and hemicellulose) and saturated $\mathrm{C}-\mathrm{H}$ stretching vibration $\left(-\mathrm{CH}_{2}\right.$ and $\left.-\mathrm{CH}_{3}\right)$ in cellulose ${ }^{3}$. Compared with Sp, Ms had more surface $\mathrm{O}-\mathrm{H}$ groups and aliphatic groups $\left(-\mathrm{CH}_{2}\right.$ and $\left.-\mathrm{CH}_{3}\right)$, but the proportions of these groups were lower in $\mathrm{Sa}$ and $\mathrm{Sb}$. Both incineration and pyrolysis ( $\mathrm{Sa}$ and $\mathrm{Sb}$ ) could remove large amounts of cellulose and hemicellulose from $\mathrm{Sp}^{6,25}$ through depolymerization and decomposition, correspondingly reducing the surface $\mathrm{O}-\mathrm{H}$ and aliphatic groups. The peak at $1734 \mathrm{~cm}^{-1}$ was attributed to unionized $\mathrm{C}=\mathrm{O}$ stretching of carboxylic acid, which was only observed in Sp. The band at $1616 \sim 1647 \mathrm{~cm}^{-1}$ was assigned to stretching in aromatic rings from lignin ${ }^{8}$. Relative to Sp, Ms also had an advantage in terms of aromaticity, and incineration and pyrolysis (Sa and Sb) eliminated a part of lignin and weakened the aromaticity of $\mathrm{Sp}$. The above changes in the functional groups of Sa and $\mathrm{Sb}$ relative to $\mathrm{Sp}$ were all similar to those of Park et al. ${ }^{29}$. The peak observed at $1373 \sim 1419 \mathrm{~cm}^{-1}$ corresponded to the aliphatic deformation of $\mathrm{CH}_{2}$ or $\mathrm{CH}_{3}$ group or $\mathrm{O}-\mathrm{H}$ group of phenols ${ }^{19,29,30}$. Park et al. ${ }^{29}$ also concluded that this peak would disappear in Ms after the modification with citric acid. Incineration of rice straw (Sa) was more conducive to the increase of these functional groups. The peak at $1036 \sim 1088 \mathrm{~cm}^{-1}$ was attributed to the stretching vibration of $\mathrm{C}-\mathrm{O}$ or $\mathrm{C}-\mathrm{O}-\mathrm{C}$ in cellulose and hemicelluloses ${ }^{31,32}$. Both $\mathrm{Sa}$ and $\mathrm{Sb}$ had greater advantages over $\mathrm{Sp}$ in terms of the amount of functional groups. These functional groups had the ability to some extent to bind Cd(II) by donation of an electron pair from these groups to form complexes with Cd(II) in solution ${ }^{33}$. The absorption bands at $793 \sim 798 \mathrm{~cm}^{-1}$ and $461 \sim 467 \mathrm{~cm}^{-1}$ were related to Si-O vibrations, in accordance with the siliceous nature of the ashes ${ }^{31}$. The peak at $461 \sim 467 \mathrm{~cm}^{-1}$ was attributed to Si-O bending vibration, indicating of the silica presence ${ }^{34}$. There was no peak at $461 \sim 467 \mathrm{~cm}^{-1}$ in Ms, indicating that a portion of silica was removed from rice straw after its modification with citric acid. Our result is consistent with the conclusion of Rocha et al..$^{34}$ However, incineration and pyrolysis (Sa and $\mathrm{Sb}$ ) greatly reduced the volume of $\mathrm{Sp}$, and thus making the Si content concentrated and increased in Sa and Sb. The ordering of the Si content in the four adsorbents was also indirectly reflected in the FTIR spectra, which is in agreement with the actual Si measurement results. It could be inferred that compared with $\mathrm{Sp}$, Ms hold more surface $\mathrm{O}-\mathrm{H}$ groups, aliphatic groups $\left(-\mathrm{CH}_{2}\right.$ and $\left.-\mathrm{CH}_{3}\right)$ and aromatic rings 

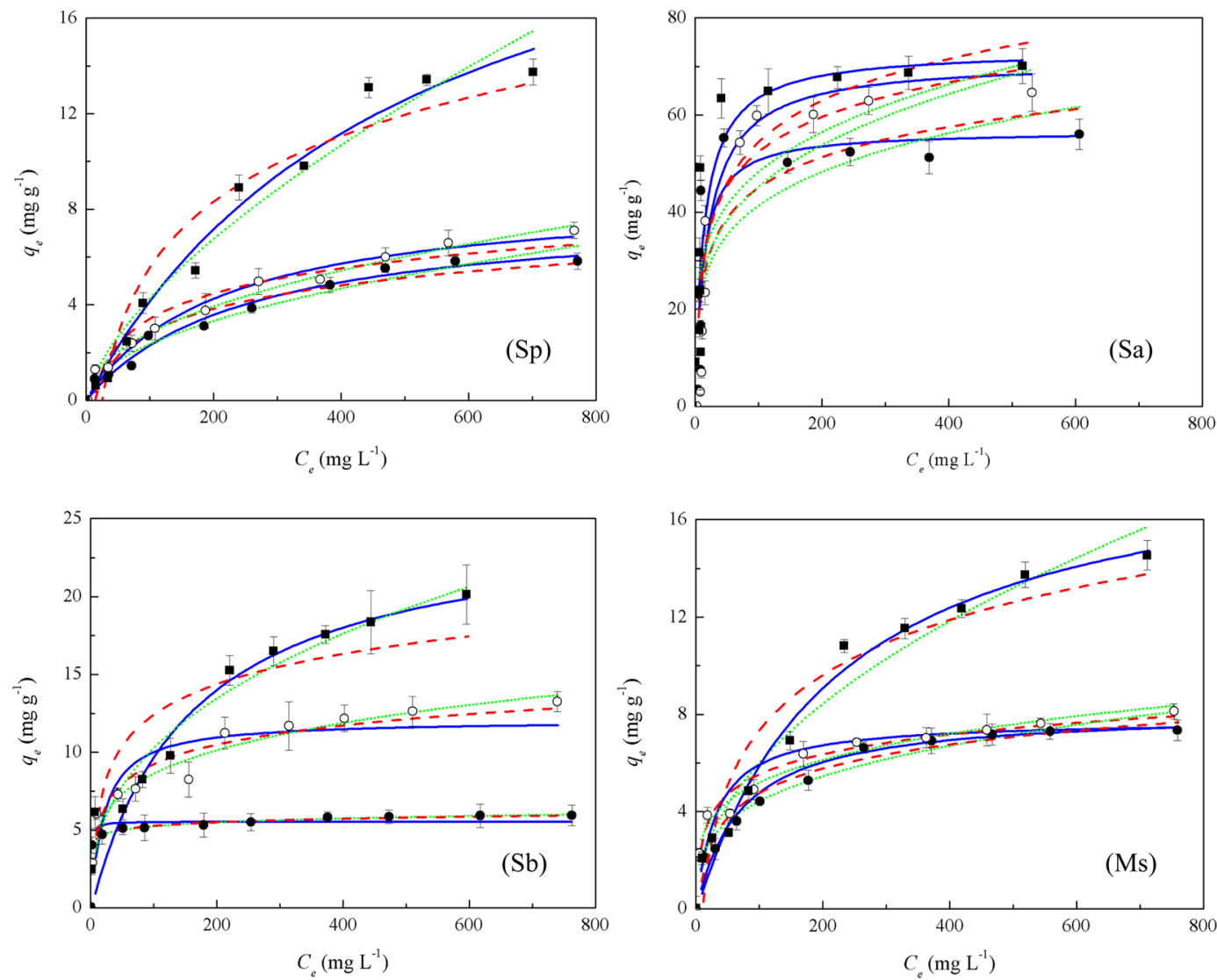

- $298 K$ O $308 K$ • $318 K$

Figure 3. Effect of initial Cd(II) concentration and temperature on the adsorption of Cd(II) onto four rice straw adsorbents. The fitted results of the Langmuir, Freundlich and Temkin models were represented by a solid, short dot, and dash line, respectively. Sp, rice straw powder; Sa, rice straw ash; Sb, rice straw biochar; Ms, modified rice straw.

after the modification with citric acid, while Sa and Sb had more phenolic, $\mathrm{C}-\mathrm{O}$ or $\mathrm{C}-\mathrm{O}-\mathrm{C}$, and Si-O groups. The characteristics of these functional groups all contributed to the increase in the adsorption capacity of Cd(II).

Adsorption isotherms. The reaction temperature of the system plays an important role in adsorption capacity ${ }^{6}$. The adsorption isotherm results are presented in Fig. 3. The results demonstrated that the adsorption capacity of Cd(II) with the four adsorbents increased until the $\mathrm{Cd}(\mathrm{II})$ adsorption reached the state of equilibrium and saturation. The initial Cd(II) concentration in the solution provided an important driving force to overcome all mass-transfer resistance for Cd(II) ions between the aqueous and solid phases ${ }^{6}$. The collision efficiency between $\mathrm{Cd}(\mathrm{II})$ and the adsorbent increased with the increase in the initial Cd(II) concentration in the solution. The increase in adsorption capacity was due to the increase in the driving force of Cd(II) to the adsorption $\operatorname{sites}^{35}$. However, the adsorption capacity of Cd(II) was no longer enhanced and remained almost constant after saturation. This was due to the lack of binding sites on the adsorbent for adsorbing Cd(II) at higher Cd(II) concentrations ${ }^{33}$. When Sp and Ms were used as the adsorbents, there was no obvious difference between the adsorption capacities of Cd(II) at $298 \mathrm{~K}$ and $308 \mathrm{~K}$, but the highest temperature at $318 \mathrm{~K}$ resulted in greater adsorption capacity than the two lower temperatures. However, when $\mathrm{Sa}$ and $\mathrm{Sb}$ were utilized as the adsorbents, the adsorption capacity of Cd(II) increased gradually with the increase in temperature from $298 \mathrm{~K}$ to $318 \mathrm{~K}$. The adsorption of $\mathrm{Cd}$ (II) onto the adsorbent with a larger SSA was more sensitive to the temperature than that with a smaller SSA. A higher SSA of an adsorbent indicated more adsorption sites, contact area and surface functional groups ${ }^{27}$. Therefore, the adsorbent with a higher SSA was more susceptible to temperature change and thus the thermal motion of the molecule. Increased temperature could increase the mobility of Cd(II) and produce a swelling effect within the internal structure of the adsorbent enabling Cd(II) to penetrate further ${ }^{36}$.

The adsorption capacity of Cd(II) at $298 \mathrm{~K}$ had the following order: $\mathrm{Sa}>\mathrm{Sb} \approx \mathrm{Ms}>\mathrm{Sp}$. Specifically, when the initial Cd(II) concentration was $0 \sim 120 \mathrm{mg} \cdot \mathrm{L}^{-1}$, the adsorption capacity for Cd(II) was greater with Ms than Sb, but when the initial Cd(II) concentration was in the range of $120 \sim 800 \mathrm{mg} \cdot \mathrm{L}^{-1}$, Sb had a higher adsorption capacity than Ms. Different from the above trends, the adsorption capacities of the four adsorbents for Cd(II) at $308 \mathrm{~K}$ and $318 \mathrm{~K}$ followed the order: $\mathrm{Sa}>\mathrm{Sb}>\mathrm{Ms}>\mathrm{Sp}$. This is consistent with the order of the SSA of four adsorbents, which could reflect the adsorption capacities of the adsorbents indirectly. A larger SSA meant more adsorption 


\begin{tabular}{|c|c|c|c|c|c|c|c|c|c|c|}
\hline \multirow[b]{2}{*}{ Treatments } & \multirow[b]{2}{*}{$\begin{array}{l}\text { Temperature } \\
(K)\end{array}$} & \multicolumn{3}{|l|}{ Langmuir } & \multicolumn{3}{|l|}{ Freundlich } & \multicolumn{3}{|l|}{ Temkin } \\
\hline & & $q_{m}\left(\mathrm{mg} \mathrm{g}^{-1}\right)$ & $K_{L}\left(\mathrm{~L} \mathrm{mg}^{-1}\right)$ & $R^{2}$ & $\begin{array}{l}K_{F}\left(\mathbf{m g}^{(1-1 / n)}\right. \\
\left.\mathrm{g}^{-1} \mathbf{L}^{1 / n}\right)\end{array}$ & $1 / n$ & $R^{2}$ & $B_{1}$ & $K_{T}$ & $R^{2}$ \\
\hline \multirow{3}{*}{$\mathrm{Sp}$} & 298 & 8.00334 & 0.00403 & 0.97041 & 0.24775 & 0.49038 & 0.95810 & 1.41157 & 0.07457 & 0.93204 \\
\hline & 308 & 8.76246 & 0.00467 & 0.96685 & 0.34308 & \begin{tabular}{|l|}
0.46124 \\
\end{tabular} & 0.98589 & 1.51178 & 0.09591 & \begin{tabular}{|l|}
0.94104 \\
\end{tabular} \\
\hline & 318 & 25.2405 & 0.00199 & 0.97643 & 0.20699 & \begin{tabular}{|l|}
0.65831 \\
\end{tabular} & 0.95180 & 3.96250 & 0.04058 & \begin{tabular}{|l|}
0.92862 \\
\end{tabular} \\
\hline \multirow{3}{*}{$\mathrm{Sa}$} & 298 & 56.73956 & 0.0833 & 0.72283 & 15.22602 & 0.21885 & 0.56832 & 9.00016 & 1.47786 & 0.72848 \\
\hline & 308 & 70.04386 & 0.04055 & 0.91422 & 11.74713 & 0.29859 & 0.74798 & 13.86945 & 0.40946 & 0.89936 \\
\hline & 318 & 72.80991 & 0.05567 & 0.77991 & 14.82427 & 0.26600 & 0.65398 & 12.89211 & 0.73158 & 0.78507 \\
\hline \multirow{3}{*}{$\mathrm{Sb}$} & 298 & 5.5494 & 1.18848 & 0.62414 & 3.88294 & 0.06518 & 0.98366 & 0.32618 & 106895.0 & 0.99777 \\
\hline & 308 & 12.08095 & \begin{tabular}{|l|}
0.04896 \\
\end{tabular} & 0.76533 & 2.99239 & \begin{tabular}{|l|}
0.22961 \\
\end{tabular} & 0.94509 & 1.76692 & 1.87956 & 0.95812 \\
\hline & 318 & 25.1658 & 0.00632 & 0.88818 & 1.71175 & 0.38917 & 0.94648 & 2.77699 & 0.88637 & 0.85144 \\
\hline \multirow{3}{*}{ Ms } & 298 & 8.14353 & 0.0142 & 0.94030 & 1.12171 & \begin{tabular}{|l|}
0.29845 \\
\end{tabular} & 0.94945 & 1.42423 & 0.28727 & \begin{tabular}{|l}
0.96985 \\
\end{tabular} \\
\hline & 308 & 7.7523 & 0.03237 & 0.84066 & 1.76356 & \begin{tabular}{|l|}
0.23455 \\
\end{tabular} & 0.96661 & 1.17731 & 1.10837 & \begin{tabular}{|l|}
0.97634 \\
\end{tabular} \\
\hline & 318 & 19.32293 & 0.00446 & 0.97593 & 0.63067 & 0.48946 & 0.96220 & 3.27095 & 0.09383 & 0.92453 \\
\hline
\end{tabular}

Table 2. Adsorption equilibrium constants obtained from Langmuir, Freundlich and Temkin isotherms in the adsorption of Cd(II) onto the four rice straw adsorbents. Sp, rice straw powder; Sa, rice straw ash; Sb, rice straw biochar; Ms, modified rice straw.

sites, i.e., greater adsorption capacity ${ }^{37}$. This is similar to the report by Wu et al. ${ }^{3}$. Although the SSAs of Ms and $\mathrm{Sp}$ were almost equal, the introduced, free carboxyl groups from citric acid could increase the net negative charges on the rice straw fiber, thereby increasing its adsorption capacity for $\mathrm{Cd}(\mathrm{II})^{7}$. When the temperature was set at $318 \mathrm{~K}$ and the initial concentration Cd(II) was set to $800 \mathrm{mg} \cdot \mathrm{L}^{-1}$, the adsorption amount of Cd(II) by Sa reached $68.7 \mathrm{mg} \cdot \mathrm{g}^{-1}$. This was the highest adsorption value out of the four rice straw adsorbents, which was much higher than the results of forest biowastes, but still less than that from the cashew nutshell treated with $\mathrm{H}_{2} \mathrm{SO}_{4}$ $\left(436.7 \mathrm{mg} \cdot \mathrm{g}^{-1}\right)$ and the result from orange peel modified with $\mathrm{KCl}\left(125.6 \mathrm{mg} \cdot \mathrm{g}^{-1}\right)^{15}$.

Finally, these results were fitted with the Langmuir, Freundlich, and Temkin isotherm models, and the adsorption constants and correlation coefficients derived from the isotherms at different temperatures are presented in Table 2. Comparing the mean values of $R^{2}$ at the three different temperatures for each fitting equation under the same adsorbent, the fitting effects of Langmuir and Freundlich equations were better than those of the Temkin equation on Sp; the fitting effects of Langmuir and Temkin equations were better than those of the Freundlich equation on Sa; and the fitting effects of Freundlich and Temkin equations were better than those of the Langmuir equation on $\mathrm{Sb}$ and $\mathrm{Ms}$. It could be clearly seen that the maximum adsorption capacity $\left(q_{m}\right)$ of the Langmuir equation for the four adsorbents was greater at $318 \mathrm{~K}$ than $298 \mathrm{~K}$ and $308 \mathrm{~K}$. The $K_{F}$ value in the Freundlich equation was a measure of the degree of adsorption. The higher $K_{F}$ values at lower temperatures indicated that more sorption would be expected at these temperatures ${ }^{38}$. As shown in Fig. 3, the $K_{F}$ value of Cd(II) adsorbed by Sb was the largest at $298 \mathrm{~K}$ out of the three temperatures, indicating more sorption of $\mathrm{Cd}(\mathrm{II})$ on the rice straw biochar would be expected at $298 \mathrm{~K}$.

All values of $1 / \mathrm{n}$ less than 1 in Table 2 indicated the favorable nature of adsorption of Cd(II) onto the four rice straw adsorbents ${ }^{25}$, and the adsorption capacity was only slightly suppressed at a lower initial concentration of $\mathrm{Cd}(\mathrm{II})$. This isotherm did not predict any saturation of Cd(II) by the adsorbent; thus, infinite surface coverage was predicted mathematically, indicating multilayer adsorption of $\mathrm{Cd}(\mathrm{II})$ on the surfaces of rice straw adsorbents ${ }^{39}$.

The $R_{L}$ and thermodynamic parameters were calculated according to Eqs. (7)-(9) and are presented in Table 3. The $R_{L}$ parameter gave an important sign for the possibility that the adsorption process might be irreversible $\left(R_{L}=0\right)$, favorable $\left(0<R_{L}<1\right)$, linearly adsorbed $\left(R_{L}=1\right)$ or unfavorable $\left(R_{L}>1\right)^{24}$. It can be seen from Table 3 that the $R_{L}$ values in Cd(II) adsorption of the four adsorbents was in the range of $0 \sim 1$, indicating that the adsorption was a favorable process. This is consistent with the findings of Ding et al. ${ }^{14}$. A negative value for $\Delta G^{\circ}$ occurred only when Cd(II) was adsorbed by Sb at $298 \mathrm{~K}$, indicating the adsorption process of Cd(II) onto the rice straw biochar at $298 \mathrm{~K}$ was thermodynamically feasible and of spontaneous nature. However, all other $\Delta G^{\circ}$ s were positive, suggesting the nonspontaneous nature of the adsorption process. It was meant an energy barrier existed during adsorption ${ }^{40}$. The nonspontaneous nature of $\mathrm{Cd}(\mathrm{II})$ adsorption in our study is similar to that reported by Albadarin et al ${ }^{41}$. The negative values of $\Delta H^{\circ}$ for $\mathrm{Cd}(\mathrm{II})$ adsorption onto the four adsorbents confirmed the exothermic nature of the adsorption process ${ }^{13,38}$, and the negative $\Delta S^{\circ}$ values reflected the order of adsorption increased during the adsorption process ${ }^{40}$.

Adsorption kinetics. The Cd(II) adsorption capacities of the four adsorbents increased with contact time and then stabilized when an equilibrium was reached (Fig. 4). During the first $240 \mathrm{~min}$, the adsorption rate of $\mathrm{Cd}$ (II) with the four adsorbents reached more than $50 \%$, and as the temperature increased, the adsorption rate of each adsorbent was enhanced.

The adsorption of Cd(II) by rice straw is a rapid process $^{14}$. Figure 4 presents the kinetics of Cd(II) adsorption onto the four adsorbents. The adsorption capacities of these four adsorbents increased with contact time and then stabilized when an equilibrium was reached. This is consistent with the findings of Zhang et al. ${ }^{20}$. During the first $240 \mathrm{~min}, \mathrm{Cd}(\mathrm{II})$ in the solution was rapidly adsorbed by the four adsorbents. The adsorption capacity of Cd(II) by $\mathrm{Sp}$ accounted for $63.2 \%, 94.8 \%$, and $97.0 \%$ of the final adsorption rate at the contact time of 1440 min under 


\begin{tabular}{|c|c|c|c|c|c|}
\hline Treatments & Temperature $(K)$ & $\Delta G^{\circ}\left(\mathrm{kJ} \mathrm{g}^{-1} \mathrm{~mol}^{-1}\right)$ & $\Delta H^{\circ}\left(\mathrm{Jg}^{-1} \mathrm{~mol}^{-1}\right)$ & $\Delta S^{\circ}\left(\mathrm{Jg}^{-1} \mathrm{~mol}^{-1} \mathrm{~K}^{-1}\right)$ & $R_{L}$ \\
\hline \multirow{3}{*}{$\mathrm{Sp}$} & 298 & 13.66 & -27.76 & -0.14 & $0.1988 \sim 1$ \\
\hline & 308 & 13.74 & & & $0.1764 \sim 1$ \\
\hline & 318 & 16.44 & & & $0.3344 \sim 1$ \\
\hline \multirow{3}{*}{$\mathrm{Sa}$} & 298 & 6.16 & -15.89 & -0.07 & $0.0119 \sim 1$ \\
\hline & 308 & 8.21 & & & $0.0241 \sim 1$ \\
\hline & 318 & 7.64 & & & $0.0176 \sim 1$ \\
\hline \multirow{3}{*}{$\mathrm{Sb}$} & 298 & -0.43 & -206.35 & -0.69 & $0.0008 \sim 1$ \\
\hline & 308 & 7.73 & & & $0.0200 \sim 1$ \\
\hline & 318 & 13.39 & & & $0.1366 \sim 1$ \\
\hline \multirow{3}{*}{ Ms } & 298 & 10.54 & -45.63 & -0.19 & $0.0658 \sim 1$ \\
\hline & 308 & 8.78 & & & $0.0300 \sim 1$ \\
\hline & 318 & 14.31 & & & $0.1832 \sim 1$ \\
\hline
\end{tabular}

Table 3. Thermodynamic parameters for the adsorption of Cd(II) onto the four rice straw adsorbents. Sp, rice straw powder; Sa, rice straw ash; Sb, rice straw biochar; Ms, modified rice straw.
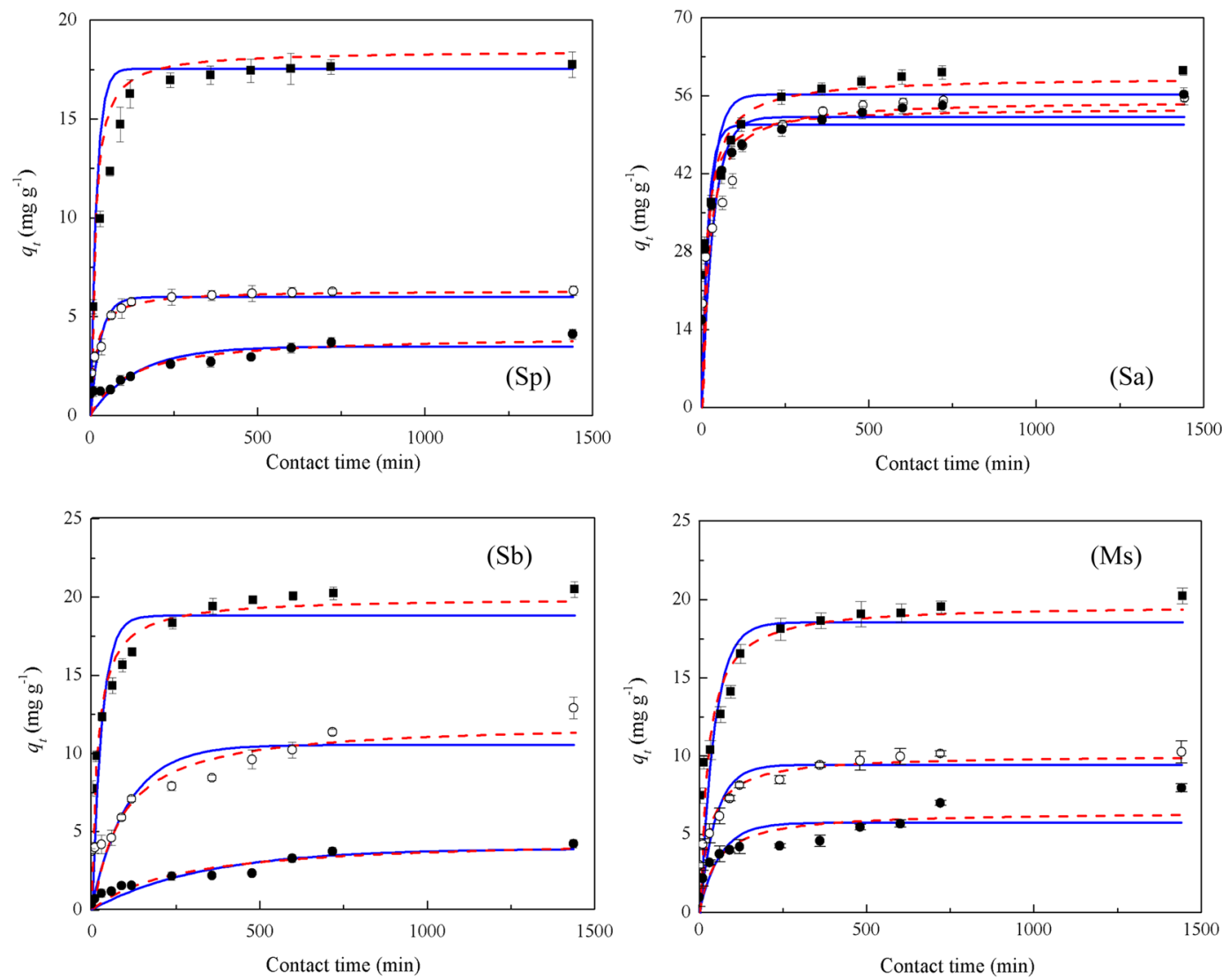

- $298 K \quad 0308 K$

$318 K$

Figure 4. Effect of contact time on the adsorption of $\mathrm{Cd}(\mathrm{II})$ onto the four rice straw adsorbents. The fitted results of the Lagergren's pseudo-first-order and pseudo-second-order models are represented by a solid and short dot line, respectively. Sp, rice straw powder; Sa, rice straw ash; Sb, rice straw biochar; Ms, modified rice straw.

298,308 and $318 K$, respectively. Similarly, the adsorption rates were $88.8 \%, 91.3 \%$, and $92.1 \%$ for Sa, $50.3 \%$, $61.0 \%$, and $89.5 \%$ for $\mathrm{Sb}$, and $53.2 \%, 82.6 \%$, and $89.5 \%$ for Ms of the final adsorption rate at 1440 min under 298, 308 and $318 \mathrm{~K}$, respectively. It was seen that in the first $240 \mathrm{~min}$, the adsorption of $\mathrm{Cd}(\mathrm{II})$ by the four adsorbents reached more than $50 \%$ of the final adsorption capacity regardless of temperature; as the temperature was raised, the adsorption capacity accounting for the percentage of the final adsorption capacity increased. Considering practical operation, the optimum contact time was selected as $240 \mathrm{~min}$. The rapid adsorption during the first $240 \mathrm{~min}$ could be attributed to the availability of the abundant functional groups and empty adsorption sites on 


\begin{tabular}{|c|c|c|c|c|c|c|c|}
\hline \multirow[b]{2}{*}{ Treatments } & \multirow[b]{2}{*}{$\begin{array}{l}\text { Temperature } \\
(K)\end{array}$} & \multicolumn{3}{|c|}{ Lagergren's pseudo-first order } & \multicolumn{3}{|c|}{ Pseudo-second-order } \\
\hline & & $q_{t}\left(\mathrm{mg} \mathrm{g}^{-1}\right)$ & $\begin{array}{l}k_{1} \\
\left(\min ^{-1}\right)\end{array}$ & $R^{2}$ & $q_{t}\left(\mathrm{mg} \mathrm{g}^{-1}\right)$ & $\begin{array}{l}k_{2}\left(\mathrm{~g} \mathrm{mg}^{-1}\right. \\
\left.\mathrm{min}^{-1}\right)\end{array}$ & $R^{2}$ \\
\hline \multirow{3}{*}{$\mathrm{Sp}$} & 298 & 3.4924 & 0.0071 & 0.6975 & 4.0576 & 0.0021 & 0.7732 \\
\hline & 308 & 6.0563 & 0.0348 & 0.6893 & 6.3764 & 0.0097 & 0.7482 \\
\hline & 318 & 17.5582 & 0.0561 & 0.5047 & 18.4610 & 0.0050 & 0.6021 \\
\hline \multirow{3}{*}{$\mathrm{Sa}$} & 298 & 50.7966 & 0.0529 & 0.6981 & 53.7478 & 0.0015 & 0.8038 \\
\hline & 308 & 52.1946 & 0.0290 & 0.5632 & 55.0369 & 0.0010 & 0.7005 \\
\hline & 318 & 56.2693 & 0.0356 & 0.4534 & 59.5281 & 0.0010 & 0.5978 \\
\hline \multirow{3}{*}{$\mathrm{Sb}$} & 298 & 3.9211 & 0.0009 & 0.8395 & 4.5635 & 0.0008 & 0.8805 \\
\hline & 308 & 10.4265 & 0.0093 & 0.6137 & 11.9465 & 0.0010 & 0.7123 \\
\hline & 318 & 18.7622 & 0.0123 & 0.4801 & \begin{tabular}{|l|}
19.9148 \\
\end{tabular} & 0.0029 & 0.6300 \\
\hline \multirow{3}{*}{ Ms } & 298 & 5.7334 & 0.0161 & \begin{tabular}{|l|}
0.6294 \\
\end{tabular} & 6.4436 & \begin{tabular}{|l|}
0.0031 \\
\end{tabular} & 0.7537 \\
\hline & 308 & 9.5123 & 0.0212 & 0.6846 & 10.1284 & 0.0036 & \begin{tabular}{|l|}
0.7831 \\
\end{tabular} \\
\hline & 318 & 18.6134 & \begin{tabular}{|l|}
0.0239 \\
\end{tabular} & 0.4961 & \begin{tabular}{|l|}
19.6157 \\
\end{tabular} & 0.0023 & \begin{tabular}{|l|}
0.6240 \\
\end{tabular} \\
\hline
\end{tabular}

Table 4. Kinetic parameters obtained from kinetic models for the adsorption of Cd(II) onto the four rice straw adsorbents. Sp, rice straw powder; Sa, rice straw ash; Sb, rice straw biochar; Ms, modified rice straw.

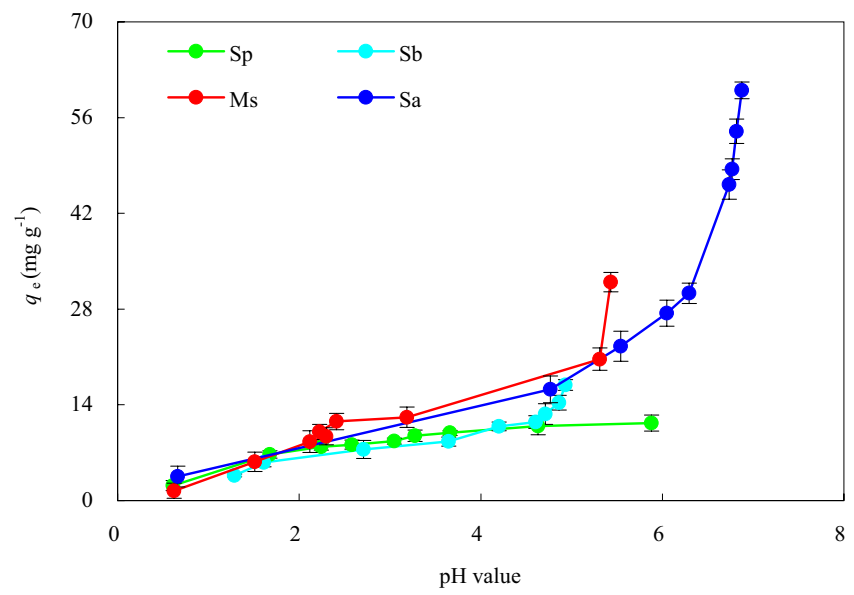

Figure 5. Effects of final $\mathrm{pH}$ on the adsorption of $\mathrm{Cd}(\mathrm{II})$ onto the four rice straw adsorbents. Sp, rice straw powder; Sa, rice straw ash; Sb, rice straw biochar; Ms, modified rice straw.

the adsorbent ${ }^{42}$; while with increase in contact time, the remaining vacant surface adsorption sites were difficult to be occupied due to repulsive forces between the solute molecules on the solid phases and slow pore diffusion or saturation of the adsorbent ${ }^{25}$.

Oeverall, Sb showed significant advantages in Cd(II) adsorption over the other three adsorbents in our study. To investigate the possible mechanism of adsorption, pseudo-first-order and pseudo-second-order adsorption models were used to fit the data. The kinetic results for the adsorption of Cd(II) by the four adsorbents are given in Table 4. The low correlation coefficient values $\left(R^{2}\right)$ at all temperatures suggest that the pseudo-first-order kinetic model be not suitable for describing the kinetics of the adsorption process. In contrast, the pseudo-second-order kinetic model showed strong fit to the data in our study, indicating that the adsorption process was chemical adsorption involving valence forces through the exchange or sharing of electrons between Cd(II) and the adsorbents ${ }^{17,25}$.

Effects of $\mathrm{pH}$. The $\mathrm{pH}$ value plays a decisive role in heavy metal ion biosorption ${ }^{26}$. Figure 5 shows the effect of the final $\mathrm{pH}$ value on the $\mathrm{Cd}$ (II) adsorption capacities of the four adsorbents. These final $\mathrm{pH}$ values were obtained at the initial $\mathrm{Cd}(\mathrm{II})$ concentration of $400 \mathrm{mg} \cdot \mathrm{L}^{-1}$ and initial $\mathrm{pH}$ value ranging from 2 to 10 . These results showed that the $\mathrm{Cd}(\mathrm{II})$ adsorption capacities of the four adsorbents were less at low $\mathrm{pH}$ values. The following mechanisms could explain this phenomenon. Firstly, the protonation of functional groups in the adsorbents made the number of available functional groups decreased. There existed electrostatic repulsion between the protonated functional groups and the positively charged $\mathrm{Cd}(\mathrm{II})^{14}$, which could impede the reaction of the adsorbents with $\mathrm{Cd}(\mathrm{II})^{26}$. Secondly, the surface active adsorption sites of the adsorbents were occupied by $\mathrm{H}(\mathrm{I})$ and $\mathrm{H}_{3} \mathrm{O}(\mathrm{I})$, which prevented Cd(II) from approaching the adsorption sites on the adsorbents ${ }^{43}$.

The adsorption capacity of Cd(II) increased with the increase of initial $\mathrm{pH}$ in the solution regardless of adsorbent type. At higher $\mathrm{pH}$ values, the lower number of $\mathrm{H}(\mathrm{I})$ and a greater number of ligands with negative charges resulted in greater $\mathrm{Cd}(\mathrm{II})$ biosorption ${ }^{33}$. When there were more negative charges on the adsorbent's surface, 


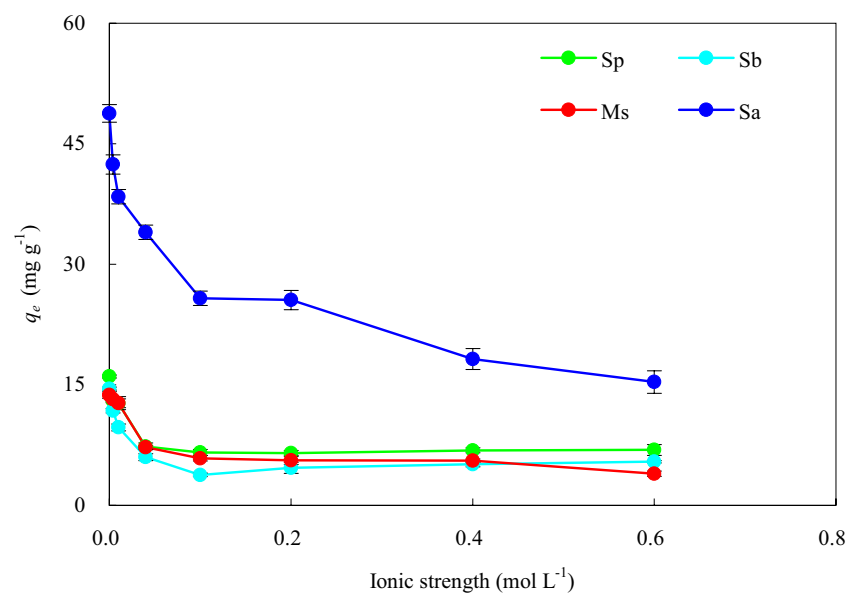

Figure 6. Effect of initial ionic strength on the adsorption of $\mathrm{Cd}(\mathrm{II})$ onto the four rice straw adsorbents. Sp, rice straw powder; Sa, rice straw ash; Sb, rice straw biochar; Ms, modified rice straw.

the electrostatic interactions were enhanced between the adsorbent and Cd(II) ${ }^{44}$, and the adsorption of Cd(II) was enhanced ${ }^{40}$. Another aspect that should be considered was the metal speciation in solution which was also $\mathrm{pH}$-dependent. An increase in solution $\mathrm{pH}$ resulted in further hydrolysis of $\mathrm{Cd}(\mathrm{II})^{45}$, in which several low-soluble hydroxyl complexes such as $\mathrm{Cd}(\mathrm{OH})_{2}$ and $\mathrm{Cd}(\mathrm{OH})_{3}{ }^{-}$might be formed $^{46}$. Thus, the maximum $\mathrm{Cd}(\mathrm{II})$ adsorption capacities of $11.3,60.0,16.9$ and $31.9 \mathrm{mg} \cdot \mathrm{g}^{-1}$ were obtained for $\mathrm{Sp}, \mathrm{Sa}, \mathrm{Sb}$, and $\mathrm{Ms}$, respectively, at the greatest $\mathrm{pH}$ value.

After $\mathrm{Cd}(\mathrm{II})$ adsorption, the final $\mathrm{pH}$ values of the equilibrium solutions from $\mathrm{Sp}$, Sa, and $\mathrm{Sb}$ to Ms were decreased to $5.88,6.88,4.93$, and 5.43, respectively. Obviously, more organic functional groups with $\mathrm{H}(\mathrm{I})$ in the adsorbents participated in the exchange reaction. It led to more $\mathrm{H}(\mathrm{I})$ entering the solution and buffering the increase in $\mathrm{pH}$ value ${ }^{26}$. In modification of Sp to Sb, the buffer capacity to alkali was maximized. This was due to that fact that the preparation of biochar $(\mathrm{Sb})$ produced organic acids and phenolic substances that lowered the $\mathrm{pH}$ in the equilibrium solution ${ }^{47}$. However, Sa had a relatively weak buffering capacity for alkali, owing to its higher $\mathrm{Ca}$ and $\mathrm{Mg}$ contents $^{48}$, so the $\mathrm{Cd}(\mathrm{II})$ adsorption capacity was greatly improved in Sa with the increase in solution $\mathrm{pH}$.

Effects of ionic strength. The effect of ionic strength on Cd(II) adsorption on the four adsorbents was achieved and examined through varying the concentrations of additive $\mathrm{NaCl}$ from 0 to $0.6 \mathrm{~mol} \cdot \mathrm{L}^{-1}$. As shown in Fig. 6, the adsorption of Cd(II) onto the four adsorbents was obviously affected by ionic strength. The Cd(II) adsorption with $\mathrm{Sa}$ and $\mathrm{Ms}$ decreased gradually with an increase in $\mathrm{NaCl}$ concentration. A reasonable explanation lay in that there was competitive adsorption between $\mathrm{Cd}(\mathrm{II})$ and $\mathrm{Na}(\mathrm{I})$; in other words, $\mathrm{Na}(\mathrm{I})$ competed with $\mathrm{Cd}(\mathrm{II})$ for the adsorption sites during the sorption process under the four adsorbents ${ }^{49}$. At a lower ionic strength, more functional groups from Sa and Ms were available for Cd(II) adsorption, thus the effect of $\mathrm{Na}$ (I) on Cd(II) adsorption was insignificant. However, when the ionic strength was higher, the competition between Cd(II) and $\mathrm{Na}(\mathrm{I})$ for the available adsorption sites became more important ${ }^{50}$; enhanced competition of the background electrolyte cation $(\mathrm{Na}(\mathrm{I}))$ for deprotonated adsorption sites at higher ionic strength ${ }^{51}$ resulted in lower Cd(II) adsorption. Similar results were reported by Chen et al..$^{52}$ for Cd(II) adsorption by bentonite. But for Sp and Sb, as the ionic strength $(\mathrm{Na}(\mathrm{I})$ concentration) increased, the adsorption capacities of $\mathrm{Cd}$ (II) decreased first and then increased slightly. The inhibiting effect of lower $\mathrm{Na}(\mathrm{I})$ concentrations on $\mathrm{Cd}(\mathrm{II})$ adsorption was explained by the competition between $\mathrm{Na}(\mathrm{I})$ and $\mathrm{Cd}(\mathrm{II})$ for the limited adsorption sites on the surfaces of adsorbents $\mathrm{s}^{53}$. However, a higher concentration of $\mathrm{Na}(\mathrm{I})\left(0.4 \sim 0.6 \mathrm{~mol} \cdot \mathrm{L}^{-1}\right)$ could not completely occupy the active adsorption sites of $\mathrm{Sp}$ and $\mathrm{Sb}$, and an electrical diffusion double layer occurred by $\mathrm{Na}(\mathrm{I})$, which caused repulsion between ions in the solution ${ }^{50}$. The Cd(II) adsorption capacities of Sp, Sa, Sb, and Ms were decreased by $57.0 \%, 68.5 \%, 62.5 \%$, and $71.4 \%$, respectively, at the ionic strength of $0.6 \mathrm{~mol} \cdot \mathrm{L}^{-1}$ compared with $0 \mathrm{~mol} \cdot \mathrm{L}^{-1}$. It could be seen that the adsorption of Cd(II) by Sa, Sb, and Ms was more susceptible to the inhibition due to the increase in ionic strength than that by Sp. The ionic strength-dependent adsorption indicated that cation exchange partly contributed to Cd(II) adsorption ${ }^{54}$. The presence of $\mathrm{Na}(\mathrm{I})$ increased the zeta potential $(\zeta)$, indicating the neutralization of deprotonated $\mathrm{Si}-\mathrm{O}-$ sites $^{55}$. The presence of $\mathrm{Si}$ in rice straw gave it an increased adsorption capacity for $\mathrm{Cd}(\mathrm{II})$ from wastewater ${ }^{6}$. Higher ionic strength tended to suppress Si release and further suppressed the adsorption ${ }^{55}$. For Sp, Sa, and Sb, the higher the ionic strength, the more the adsorption of $\mathrm{Cd}(\mathrm{II})$ on the adsorbent because of a higher portion of $\mathrm{Si}$ being inhibited as more $\mathrm{Si}-\mathrm{O}$-sites were deprotonated. Although the amount of $\mathrm{Si}$ contained in Ms was the smallest, the introduced free carboxyl groups from citric acid caused more $\mathrm{H}(\mathrm{I})$ to compete with $\mathrm{Cd}(\mathrm{II})^{56}$, so Ms was most effective in inhibiting Cd(II) adsorption.

\section{Conclusions}

Different modification methods exerted different effects on the SSA, Si content, surface morphology, and O-containing functional group of rice straw, but the adsorption capacity for Cd(II) was increased with all the modified rice straw materials relative to the raw rice straw powder $(\mathrm{Sp})$ control. Raising up the temperature $(298 \sim 318 \mathrm{~K})$, enhancing the initial Cd(II) concentration $\left(0 \sim 800 \mathrm{mg} \cdot \mathrm{L}^{-1}\right)$, prolonging the contact time 
(0 1440 $\mathrm{min})$, increasing the initial $\mathrm{pH}$ value $(2 \sim 10)$, and reducing the ionic strength $\left(0 \sim 0.6 \mathrm{~mol} \cdot \mathrm{L}^{-1}\right)$ were all beneficial for increasing the adsorption of Cd(II) by the four adsorbents. rice straw ash, which had the largest SSA, possessed the largest adsorption capacity for Cd(II). Only the adsorption of Cd(II) by the rice straw biochar at $298 \mathrm{~K}$ was spontaneous, and surprisingly, all other adsorptions were nonspontaneous. The Cd(II) adsorptions by the four adsorbents were all chemical and were favorable, exothermic and order-increase processes. The pseudo-second-order model showed a strong fit for the adsorption kinetics of Cd(II) by the adsorbents. The adsorption capacity of $\mathrm{Cd}(\mathrm{II})$ by the adsorbents was less at low $\mathrm{pH}$ values and increased with the increase of initial $\mathrm{pH}$ in the solution. Due to higher Si content in rice straw ash and biochar and more free carboxyl group with citric acid modified rice straw, the inhibiting effect on Cd(II) adsorption due to the increase in ionic strength was greater under rice straw ash, rice straw biochar and citric acid modified rice straw than that with rice straw power. In our study, the optimum condition for $\mathrm{Cd}(\mathrm{II})$ adsorption by rice straw adsorbents turned out to be the combination of temperature at $318 \mathrm{~K}$, initial Cd(II) concentration of $800 \mathrm{mg} \cdot \mathrm{L}^{-1}$, contact time of $240 \mathrm{~min}$, and no $\mathrm{Na}(\mathrm{I})$ interference. If more updated instruments, such as nitrogen adsorption-desorption and Transmission electron microscope, were used to examine Cd(II) adsorption, more interesting results would be obtained. Rice is a gramineous plant species with strong Cd(II) enrichment ability. Cd(II) is the most common toxic metal in paddy fields threatening safe rice supply. Future research needs to focus on the removal of Cd(II) from rice paddy fields in situ using local rice straw ash prepared by ashing with no incineration to reduce the pollution of Cd(II) in rice (both grains and straws) and thus resulting in safer rice production and healthier environment.

Received: 19 August 2019; Accepted: 6 November 2019;

Published online: 28 November 2019

\section{References}

1. Wang, R. Z. et al. Investigating the adsorption behavior and the relative distribution of $\mathrm{Cd}^{2+}$ sorption mechanisms on biochars by different feedstock. Bioresource Technol. 261, 265-271 (2018).

2. Cui, X. Q. et al. Potential mechanisms of cadmium removal from aqueous solution by Canna indica derived biochar. Sci. Total Environ. 562, 517-525 (2016).

3. Wu, M. J., Liu, H. Y. \& Yang, C. P. Effects of pretreatment methods of wheat straw on adsorption of Cd(II) from waterlogged paddy soil. Int. J. Environ. Res. Public Health 16, 205 (2019).

4. Abidin, C. Z. A., Ibrahim, N., Ridwan, F. \& Selamat, S. Removal of $\mathrm{Cu}(\mathrm{II})$ from industrial effluents by citric acid modified rice straw. Bioremediation Science \& Technology Research 2(1), 23-28 (2014).

5. Krishnani, K. K. Lignocellulosic wheat straw-derived ion-exchange adsorbent for heavy metals removal. Appl. Biochem. Biotech. 178(4), 670-686 (2016).

6. Ahmaruzzaman, M. \& Gupta, V. K. Rice husk and its ash as low-cost adsorbents in water and wastewater treatment. Ind. Eng. Chem. Res. 50(24), 13589-13613 (2011).

7. Gong, R. M., Jin, Y. B., Chen, F. Y., Chen, J. \& Liu, Z. L. Enhanced malachite green removal from aqueous solution by citric acid modified rice straw. J. Hazard Mater. 137(2), 865-870 (2006).

8. Asuquo, E. D., Martin, A. D. \& Nzerem, P. Evaluation of Cd(II) ion removal from aqueous solution by a low-cost adsorbent prepared from white yam (Dioscorea rotundata) waste using batch sorption. ChemEngineering 2(3), 35 (2018).

9. Awual, M. R. New type mesoporous conjugate material for selective optical copper(II) ions monitoring \& removal from polluted waters. Chem. Eng. J. 307, 85-94 (2017).

10. Awual, M. R. A facile composite material for enhanced cadmium(II) ion capturing from wastewater. J. Environ. Chem. Eng. 7, 103378 (2019).

11. Kyzas, G. Z. \& Kostoglou, M. Green adsorbents for wastewaters: a critical review. Materials 7, 333-364 (2014).

12. Amer, H., El-Gendy, A. \& El-Haggar, S. Removal of lead (II) from aqueous solutions using rice straw. Water Sci. Technol. 76(5), 1011-1021 (2017).

13. El-Sayed G. O., Dessouki H. A. \& Ibrahim S. S. Biosorption of Ni (II) and Cd (II) ions from aqueous solutions onto rice straw. Chemical Sciences Journal (2010).

14. Ding, Y., Jing, D. B., Gong, H. L., Zhou, L. B. \& Yang, X. S. Biosorption of aquatic cadmium(II) by unmodified rice straw. Bioresource Technol. 114, 20-25 (2012).

15. Pyrzynska, K. Removal of cadmium from wastewaters with low-cost adsorbents. J. Environ. Chem. Eng. 7, 102795 (2019).

16. Ye, H. P., Zhu, Q. \& Du, D. Y. Adsorptive removal of $\mathrm{Cd}(\mathrm{II})$ from aqueous solution using natural and modified rice husk. Bioresource Technol. 101, 5175-5179 (2010).

17. Guo, H. et al. Removal of cadmium(II) from aqueous solutions by chemically modified maize straw. Carbohydr. Polym. 115, 177-185 (2015).

18. Ong, S. A., Seng, C. E. \& Lim, P. E. Kinetics of adsorption of $\mathrm{Cu}(\mathrm{II})$ and $\mathrm{Cd}(\mathrm{II})$ from aqueous solution on rice husk and modified rice husk. Electron. J. Environ. Agric. Food Chem. 6(2), 1764-1774 (2007).

19. Li, B. et al. Adsorption of Cd(II) from aqueous solutions by rape straw biochar derived from different modification processes. Chemosphere 175, 332-340 (2017).

20. Zhang, H. Y. et al. Preparation of rice straw-derived biochar for efficient cadmium removal by modification of oxygen-containing functional groups. Sci. Total Environ. 631-632, 795-802 (2018).

21. Feng, Q. G., Lin, Q. Y., Gong, F. Z., Sugita, S. \& Shoya, M. Adsorption of lead and mercury by rice husk ash. J. Colloid Interface Sci. 278(1), 1-8 (2004).

22. El-Said, A. G. Biosorption of $\mathrm{Pb}(\mathrm{II})$ ions from aqueous solutions onto rice husk and its ash. J. Am. Sci. 6(10), 143 (2010).

23. Bashir, S., Zhu, J., Fu, Q. L. \& Hu, H. Q. Comparing the adsorption mechanism of Cd by rice straw pristine and KOH-modified biochar. Environ. Sci. Pollut. R. 25, 11875-11883 (2018).

24. Liu, Y. C., Zhu, X. D., Qian, F., Zhang, S. C. \& Chen, J. M. Magnetic activated carbon prepared from rice straw-derived hydrochar for triclosan removal. RSC Adv. 4, 63620-63626 (2014).

25. El-Chaghaby, G. A., Ramis, E. S. \& Ahmad, A. F. Rice straw and rice straw ash for the removal of brilliant green dye from wastewater. Asian Journal of Applied Chemistry Research 1(2), 1-9 (2018).

26. Zhang, Y. S., Liu, W. G., Xu, M., Zheng, F. \& Zhao, M. J. Study of the mechanisms of $\mathrm{Cu}^{2+}$ biosorption by ethanol/caustic-pretreated baker's yeast biomass. J. Hazard Mater. 178, 1085-1093 (2010).

27. Ma, J. et al. High-performance amino-functional graphene/CNT aerogel adsorbent for formaldehyde removal from indoor air. Aerosol Air Qual. Res. 17, 913-922 (2017).

28. Guntzer, F., Keller, C. \& Meunier, J. D. Determination of thesilicon concentration in plant material using Tiron extraction. New Phytol. 188, 902-906 (2010). 
29. Park, J. H. et al. Recycling of rice straw through pyrolysis and its adsorption behaviors for $\mathrm{Cu}$ and $\mathrm{Zn}$ ions in aqueous solution. Colloid Surface A 533, 330-337 (2017).

30. Wu, W. X. et al. Chemical characterization of rice straw-derived biochar for soil amendment. Biomass Bioenerg. 47, 268-276 (2012).

31. Roselló, J. et al. Rice straw ash: A potential pozzolanic supplementary material for cementing systems. Ind. Crop Prod. 103, 39-50 (2017).

32. Lin, C. et al. A study on adsorption of Cr (VI) by modified rice straw: Characteristics, performances and mechanism. J. Clean Prod. 196, 626-634 (2018).

33. Abdel-Ghani, N. T. \& El-Chaghaby, G. A. Biosorption for metal ions removal from aqueous solutions: a review of recent studies. International Journal of Latest Research in Science and Technology 3(1), 24-42 (2014).

34. Rocha, C. G., Zaia, D. A. M., Alfaya, R. V. D. S. \& Alfaya, A. A. D. S. Use of rice straw as biosorbent for removal of $\mathrm{Cu}(\mathrm{II}), \mathrm{Zn}(\mathrm{II})$, $\mathrm{Cd}(\mathrm{II})$ and $\mathrm{Hg}(\mathrm{II})$ ions in industrial effluents. J. Hazard Mater. 166(1), 383-388 (2009).

35. Song, T. et al. Biosorption of cadmium ions from aqueous solution by modified Auricularia Auricular matrix waste. J. Mol. Liq. 241, 1023-1031 (2017).

36. Crini, G. \& Badot, P. M. Sorption processes and pollution: Conventional and non-conventional sorbents for pollutant removal from wastewaters. Presses Univ. Franche-Comté (2011).

37. Ma, J., Xiong, Y. C. \& Yu, F. Comment on "Hierarchically porous, ultra-strong reduced graphene oxide-cellulose nanocrystal sponges for exceptional adsorption of water contaminants" by Yousefi, N., Wong, K. K. W., Hosseinidoust, Z., Sørensen, H. O., Bruns, S., Zheng, Y. \& Tufenkji, N., Nanoscale, 2018, 10, 7171 Nanoscale, 11, 12720-12722 (2019).

38. Jnr, M. H. \& Spiff, A. I. Effects of temperature on the sorption of $\mathrm{Pb}^{2+}$ and $\mathrm{Cd}^{2+}$ from aqueous solution by Caladium bicolor (Wild Cocoyam) biomass. Electron. J. Biotechn. 8(2) (2005).

39. Mobasherpour, I., Salahi, E. \& Ebrahimi, M. Thermodynamics and kinetics of adsorption of $\mathrm{Cu}$ (II) from aqueous solutions onto multi-walled carbon nanotubes. J. Saudi Chem. Soc. 18(6), 792-801 (2014).

40. Tang, C. F. et al. Comparison of the removal and adsorption mechanisms of cadmium and lead from aqueous solution by activated carbons prepared from Typha angustifolia and Salix matsudana. RSC Adv. 7, 16092-16103 (2017).

41. Albadarin, A. B., Mangwandi, C., Walker, G. M., Allen, S. J. \& Ahmad, M. N. Biosorption characteristics of sawdust for the removal of Cd (II) ions: Mechanism and thermodynamic studies. Chem. Eng. Trans. (2011).

42. Awual, M. R. et al. Ligand field effect for Dysprosium(III) and Lutetium(III) adsorption and EXAFS coordination with novel composite nanomaterials. Chem. Eng. J. 320, 427-435 (2017).

43. Zheng, L. C. et al. Preparation of cellulose derived from corn stalk and its application for cadmium ion adsorption from aqueous solution. Carbohyd. Polym. 90, 1008-1015 (2012).

44. Huang, C. P., Huang, C. P. \& Morehart, A. L. The removal of $\mathrm{Cu}(\mathrm{II})$ from dilute aqueous solutions by Saccharomyces cerevisiae. Water Res. 24, 433-439 (1999).

45. Li, W. C., Law, F. Y. \& Chan, Y. H. M. Biosorption studies on copper (II) and cadmium (II) using pretreated rice straw and rice husk. Environ. Sci. Pollut. Res. 24, 8903-8915 (2017).

46. Iqbal, M., Saeed, A. \& Zafar, S. I. FTIR spectrophotometry, kinetics and adsorption isotherms modeling, ion exchange, and EDX analysis for understanding the mechanism of $\mathrm{Cd}^{2+}$ and $\mathrm{Pb}^{2+}$ removal by mango peel waste. J. Hazard Mater. 164, 161-171 (2009).

47. Xu, X. Y., Cao, X. D. \& Zhao, L. Comparison of rice husk- and dairy manure-derived biochars for simultaneously removing heavy metals from aqueous solutions: Role of mineral components in biochars. Chemosphere 92, 955-961 (2013).

48. Ogbodo, E. N. Effect of crop residue on soil chemical properties and rice yield on an Ultisol at Abakaliki, Southeastern Nigeria. World Journal of Agricultural Sciences 7(1), 13-18 (2011).

49. Awual, M. R. et al. Selective cesium removal from radioactive liquid waste by crown ether immobilized new class conjugate adsorbent. J. Hazard. Mater. 278, 227-235 (2014).

50. Salmani, M. H., Zarei, S., Ehrampoush, M. H. \& Danaie, S. Evaluations of $\mathrm{pH}$ and high ionic strength solution effect in cadmium removal by zinc oxide nanoparticles. J. Appl. Sci. Environ. Manage. 17(4), 583-593 (2013).

51. Borrok, D. M. \& Fein, J. B. The impact of ionic strength on the adsorption of protons, $\mathrm{Pb}, \mathrm{Cd}$, and $\mathrm{Sr}$ onto the surfaces of Gram negative bacteria: testing non-electrostatic, diffuse, and triple-layer models. J. Colloid Interf. Sci. 286, 110-126 (2005).

52. Chen, Y. G., Ye, W. M., Yang, X. M., Deng, F. Y. \& He, Y. Effect of contact time, pH, and ionic strength on Cd(II) adsorption from aqueous solution onto bentonite from Gaomiaozi, China. Environ Earth Sci. 64, 329-336 (2011).

53. Vasudevan, P., Padmavathy, V. \& Dhingra, S. C. Biosorption of monovalent and divalent ions on baker's yeast. Bioresource Technol. 82, 285-289 (2002).

54. Wang, X. K. \& Liu, X. P. Effect of $\mathrm{pH}$ and concentration on the diffusion of radiostrontium in compacted bentonite-a capillary experimental study. Appl. Radiat. Isot. 61, 1413-1418 (2004).

55. Nguyen, M. N., Dultz, S. \& Guggenberger, G. Effects of pretreatment and solution chemistry on solubility of rice-straw phytoliths. Plant Nutr. Soil Sci. 177, 349-359 (2014).

56. Zhu, B., Fan, T. X. \& Zhang, D. Adsorption of copper ions from aqueous solution by citric acid modified soybean straw. J. Hazard Mater. 153, 300-308 (2008)

\section{Acknowledgements}

This work was supported by the National Key Research and Development Program of China (No. 2018YFD03002071), the National Natural Science Foundation of China (No. 41401251) and the Seed Foundation of Jilin Agricultural Science and Technology University (No. 20187004).

\section{Author contributions}

N.W., K.Y., W.H.L. and W.H.H. carried out the experiments, analyzed the results for the adsorption' data. S.W., Y.C.F., X.H.Y. and D.Y.C. fitted the thermodynamics and kinetics of adsorption curves. S.W., X.H.Y. and D.Y.C. drafted the manuscript. All authors reviewed and approved the manuscript.

\section{Competing interests}

The authors declare no competing interests.

\section{Additional information}

Correspondence and requests for materials should be addressed to S.W., X.Y. or D.C.

Reprints and permissions information is available at www.nature.com/reprints.

Publisher's note Springer Nature remains neutral with regard to jurisdictional claims in published maps and institutional affiliations. 
(c) (i) Open Access This article is licensed under a Creative Commons Attribution 4.0 International License, which permits use, sharing, adaptation, distribution and reproduction in any medium or format, as long as you give appropriate credit to the original author(s) and the source, provide a link to the Creative Commons license, and indicate if changes were made. The images or other third party material in this article are included in the article's Creative Commons license, unless indicated otherwise in a credit line to the material. If material is not included in the article's Creative Commons license and your intended use is not permitted by statutory regulation or exceeds the permitted use, you will need to obtain permission directly from the copyright holder. To view a copy of this license, visit http://creativecommons.org/licenses/by/4.0/.

(C) The Author(s) 2019 